\title{
Correlation of the oxygen and carbon isotope ratios of calcite samples from a hydrothermal ore vein
}

\author{
ISTVÁN CORNIDES ${ }^{1 *}$ and JÁNOS KISS ${ }^{2}$ \\ Department of Chemistry, Tokyo Institute of Technology, \\ O-okayama, Meguro-ku, Tokyo 152 Japan $^{1}$ \\ and Department of Mineralogy, Eötvös Loránd University, Budapest, Hungary ${ }^{2}$
}

(Received August 2, 1976)

\begin{abstract}
The variation of the carbon isotope ratio of calcite samples collected from the microcrystalline main body of a hydrothermal ore vein has been found to follow a trend opposite to that shown by the oxygen isotope ratio of the same samples. This anomalous behaviour is explained by the presumable mechanism of the formation of the vein. The "oxygen-carbon isotopic behaviour" has been found normal in the case of big single crystals of calcite from the same vein.
\end{abstract}

To elucidate some details of the formation mechanism of the hydrothermal ore veins in the MÁtra mountains, Hungary, a series of isotopic investigations were carried out by the authors (CORNIDEs et al., 1966; CoRNIDES, 1968; KISS and CoRnIDEs, 1972). By the determination of the oxygen isotope ratio of calcite samples taken at four different cross sections, information on the variation of the temperature of formation was obtained. The $\delta^{18} \mathrm{O}$ values measured have shown two minima along the cross section in all cases, indicating two maxima of temperature. The diagram of Fig. 2 is presented as an example.

This result could be considered as a strong support to the hypothesis, based on mineralogical and petrographical evidences, that the vein had been formed by two steps, the second one initiated by an abrupt dilatation of the hanging side. The more detailed description of this conception of the vein formation mechanism presented earlier (KISS and CoRNIDEs, 1972), is summarized in and illustrated by Fig. 1 .

Our investigation further revealed an unexpected type of correlation between the $\delta^{18} \mathrm{O}$ and $\delta^{13} \mathrm{C}$ data. The latter were measured for the usual correction of the oxygen isotope data.

When calcium carbonate precipitates from solution, isotopic fractionation occurs accord- ing to the following isotope exchange reactions:

$$
\begin{aligned}
& \mathrm{H}_{2}{ }^{18} \mathrm{O}+\frac{1}{3} \mathrm{CaC}^{16} \mathrm{O}_{3} \rightleftharpoons \mathrm{H}_{2}{ }^{16} \mathrm{O}+\frac{1}{3} \mathrm{CaC}^{18} \mathrm{O}_{3} \\
& { }^{13} \mathrm{CO}_{2}+\mathrm{Ca}^{12} \mathrm{CO}_{3} \rightleftharpoons{ }^{12} \mathrm{CO}_{2}+\mathrm{Ca}^{13} \mathrm{CO}_{3}
\end{aligned}
$$

If equilibrium conditions can be preserved, the extent of the isotopic fractionation depends only on the temperature of precipitation. This temperature dependence was experimentally determined for both the oxygen (e.g., O'NeIL et al., 1969) and the carbon (MALinin et al., 1967) isotope ratio. It has been found that though the extent of the fractionation is significantly greater for the oxygen isotopes, the trend of the change is the same, i.e., ${ }^{18} \mathrm{O} /{ }^{16} \mathrm{O}$ and ${ }^{13} \mathrm{C} /{ }^{12} \mathrm{C}$ isotope ratios both dearease with increasing temperature.

This positive correlation between the oxygen and carbon isotope ratios has been confirmed by several investigations of both hydrothermal calcites (e.g., SchOELL and STAHL, 1969), and limestones (e.g., Cornides, 1968). It was, therefore, rather unexpectedly found that the change in $\delta^{13} \mathrm{C}$ of vein calcite has shown a trend consistently opposite to that displayed by the $\delta^{18} \mathrm{O}$ data for the samples of all the cross sections investigated (KISS and CORNIDES, 1972). 


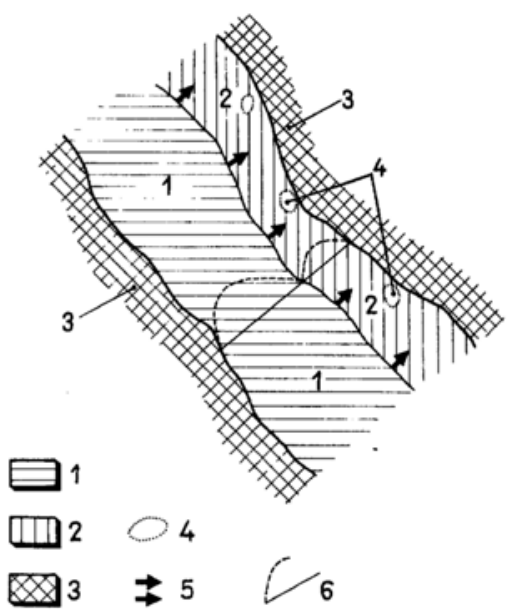

Fig. 1. Schematic representation of a part of the vein investigated.

1 and 2: parts of the vein formed in the first and the second phase, respectively. 3: andesite country rock. 4: druses. 5: direction of the dilatation of the hanging side. 6: idealized temperature distribution pattern along the vein's cross section.

Along with these measurements an isotopic investigation of several big single crystals of calcite, taken from druses of the same vein, was carried out as well. Samples were taken from various parts of the crystals, altogether thirty from three different single crystals, and $\delta^{18} \mathrm{O}$ and $\delta^{13} \mathrm{C}$ values have been measured for all samples. Significant changes in the oxygen isotope ratio were found again, indicating that the temperature of the druse-filling fluid had not been constant. In this case, however, the carbon isotope ratio was found to display essentially the same pattern of change, in agreement with the findings of the basic investigations mentioned. As an example the diagram of Fig. 3 is presented, illustrating the close qualitative similarity of the variation of the $\delta^{18} \mathrm{O}$ and $\delta^{13} \mathrm{C}$ data throughout the series of ten samples from one of the single crystals investigated. The opposite, i.e. the anomalous behaviour, experineced in the case of the samples taken from the finegrained microcrystalline calcite material of the vein's main body is illustrated by Fig. 2, displaying the $\delta^{18} \mathrm{O}$ and $\delta^{13} \mathrm{C}$ data obtained for samples from one of the cross sections investigated.

The difference between the two types of "oxygen-carbon isotopic behaviour" is obvious. In Fig. 3 (single crystal) practically all $\delta^{18} \mathrm{O}$ maxima coincide with the maxima of the $\delta^{13} \mathrm{C}$

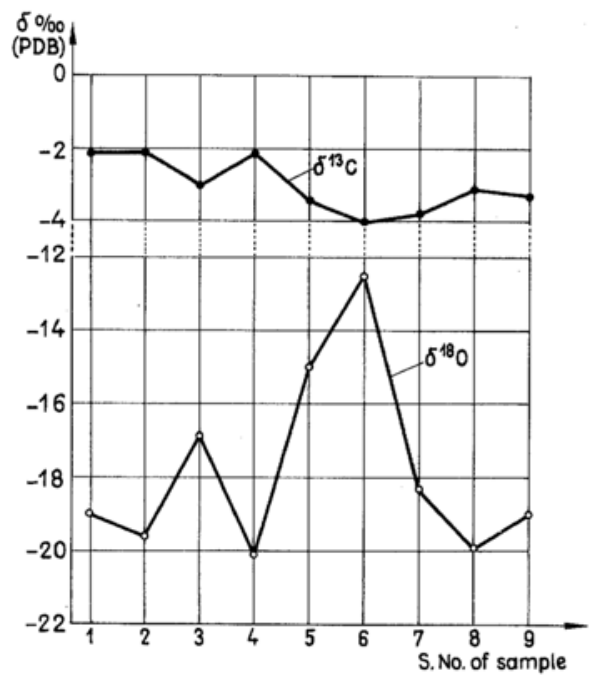

Fig. 2. Distribution of the $\delta^{13} \mathrm{C}$ and $\delta^{18} \mathrm{O}$ data along one cross section of the vein. The serial numbers of the samples on the abscissa axis indicate the sequence of the samples in the direction to the hanging side, but not their exact location or distances.

values, and this holds for the minima as well. Quite on the contrary, in Fig. 2 (micro-crystalline calcite) the maxima of the $\delta^{18} \mathrm{O}$ data correspond to the minima of the $\delta^{13} \mathrm{C}$ values, and vice versa. It is also to be mentioned that the spread of the $\delta^{13} \mathrm{C}$ data is significantly smaller in Fig. 2 than in Fig. 3. Practically the same characteristics were obtained in the case of all

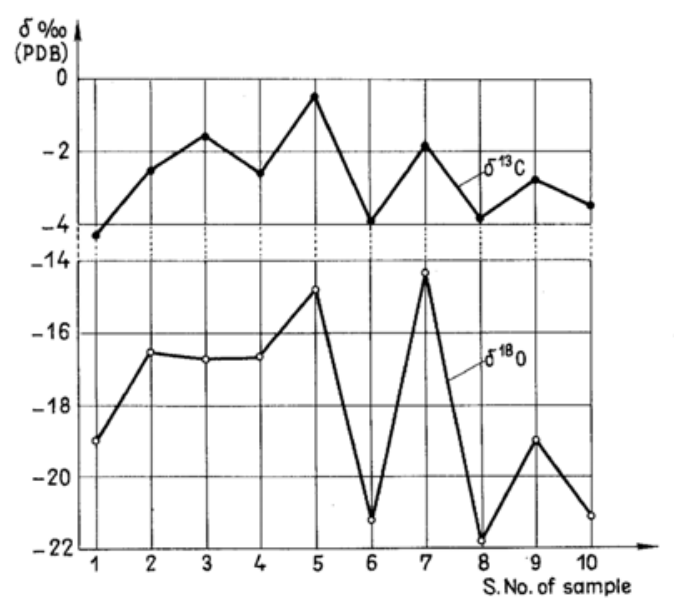

Fig. 3. Correlation of the $\delta^{13} \mathrm{C}$ and $\delta^{18} \mathrm{O}$ data of samples taken from a big single crystal. The serial numbers along the abscissa axis do not indicate in any way the location of the samples on the surface or inside the crystal. 
the other cross sections of the vein (four altogether) and big single crystals (three altogether).

To be explained is, of course, the anomalous behaviour of the fine-grained calcite that is even better visualized by plotting the two $\delta$ values against each other. In Fig. 4 the data of Fig. 2 are plotted in this way. The straight lines of negative slope instead of a positive one clearly present the anomaly in question.

Since the values of the temperature of formation calculated from the $\delta^{18} \mathrm{O}$ data, and also the temperature distribution pattern along the vein's cross sections were found to be in good agreement with what was expected on grounds of geological and mineralogical evidences, we may conclude that equilibrium distribution of the oxygen isotopes had been maintained during precipitation, corresponding at any time to the temperature of the hydrothermal solution. Any explanation of the reversed $\delta^{13} \mathrm{C}$ pattern of the microcrystalline calcite is, therefore, to be based on assuming non-equilibrium conditions for the carbon isotopes, i.e., different behaviour of the two elements during precipitation of the vein's calcite.

The reason for this different behaviour may be the fact that hydrothermal solutions cannot always be regarded as reservoirs of unlimited capacity for carbon atoms, while practically no such restrictions exist in the case of oxygen atoms, the concentration of which may be some orders of magnitude higher, than that of the $\mathrm{C}$ atoms. Furthermore, the formation of the microcrystalline calcite had obviously been taking place as a volume phenomenon, due to the simultaneous growing of very numerous crystal nuclei finely dispersed in that part of the solution, in which crystallization had been going on at a given time. This type of solid phase formation implies, in turn, both an increased rate of crystallization and a restricted diffusion of carbonate ions to the liquid phase filled with crystal nuclei. It is, therefore, quite reasonable to assume that the latter ones had consumed available carbonate in their neighbourhood, and that during this process the original, i.e. equilibrium distribution of the carbon isotopes had not been maintained. For the oxygen isotopes, however, the equilibrium distribution could have been preserved by the continuous isotopic exchange between carbonate ions and water molecules. The $\delta^{18} \mathrm{O}$ values of the calcite, therefore, reflect the temperature of crystallization. In the case of the big single crystals the supply of carbonate ions to their surface is practically unlimited and the maintenance of the equilibrium distribution depends only on the temperature, possibly for both oxygen and carbon isotopes.

The conclusion to be drawn from the above considerations would require essentially constant $\delta^{13} \mathrm{C}$ value along any of the cross sections of the vein, and this should be equal to the average $\delta^{13} \mathrm{C}$ value of the carbonate ions of the hydrothermal solution. Actually nearly constant carbon isotope ratio has been found in the case of one of the four cross sections investigated, as shown in Fig. 5, displaying a reversed correlation just at the error limit level.

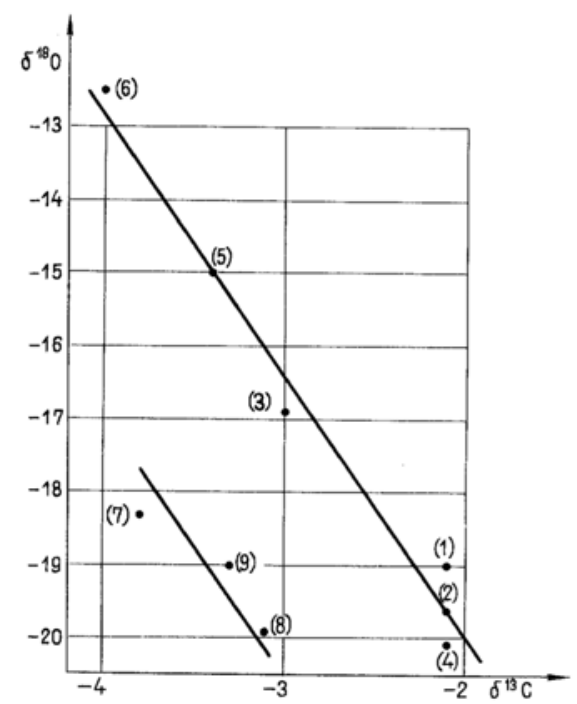

Fig. 4. The $\delta^{13} \mathrm{C}-\delta^{18} \mathrm{O}$ diagram of the samples of Fig. 2 .

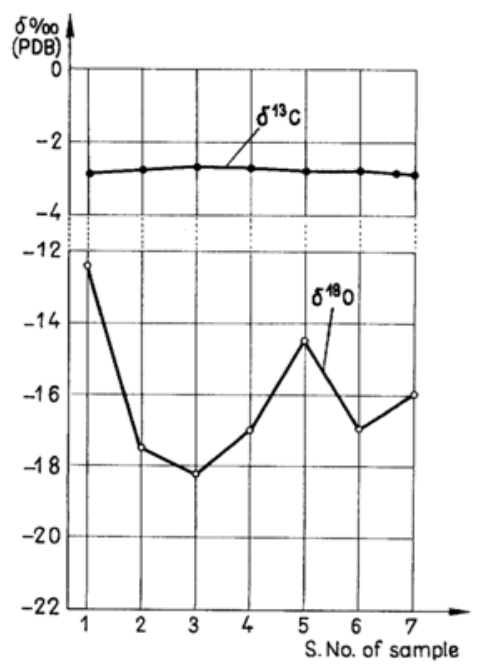

Fig. 5. Distribution of the $\delta^{13} \mathrm{C}$ and $\delta^{18} \mathrm{O}$ values along a narrow cross section of the vein. 
Reversed correlation is very much apparent in the case of the other three cross sections, and may possibly be explained as follows. The restricted diffusion of carbonate ions into the marginal regions near the walls of the crevice had been insufficient to maintain equilibrium precipitation conditions for the carbon atoms, and might have resulted in an enrichment of the heavy carbon isotope in the central regions of higher temperature, in which crystallization started later. This enrichment might have overcompensated here the effect of the higher temperature of crystallization, i.e., the decrease in the preference of the heavy isotope. As a consequence, the $\delta^{13} \mathrm{C}$ values of the calcite samples taken from this central region are relatively high, in contrast to their low $\delta^{18} \mathrm{O}$ values, that indicate correctly the higher temperature.

There had been existing, of course, two high temperature regions, one in each of the two hydrothermal processes that have formed the vein. In the case of Fig. 2 these are represented by the two sets of calcite samples of No. 1-2$3-4$ and No. 7-8-9. We place the two relatively low temperature samples Nos. 5 and 6 in the former group, i.e., we think they belong to the first part of the vein, which was formed in the first process near the hanging side of the crevice, that later (see Fig. 1) gave way to the formation of the second part of the vein.

This grouping is motivated by the diagram of Fig. 4 presenting the relationship between the two $\delta$ values. This relationship was expected and found to be linear in the case of equilibrium precipitation (e.g., RoBINSON, 1974). Nothing can be predicted, however, if equilibrium has not been preserved, of course except for the special case of constant $\delta^{13} \mathrm{C}$. The points of Fig. 4 seem to indicate a quasi-linear relationship with negative slope, if we adopt the above grouping and draw two separate straight lines, based on the acceptable assumption that the carbon isotope ratio of the hydrothermal fluid in the second phase of the vein formation process might have been somewhat different from that of the first phase.

Acknowledgment-The authors' thanks are due to Prof. S. MATSUO for reading the manuscript and the useful comments he made.

\section{REFERENCES}

CORNIDES, I. (1968) Isotope geochemical investigations in the region of the MÁtra ore deposits. Res. Rep. of the Hungarian Min. Res. Inst. No. 23-1/68.

CORNIDES, I., KISS, J. and SZEREDAY, L. (1966) Temperature de formation d'un filon de mineral dans la MÁTRA centrale d'apres la frequance relative de l'isotope ${ }^{18}$ O. Bull. Hungarian Geol. Soc. 96, 43-50.

KISS, J. and CORNIDES, I. (1972) Origin of the ore veins in MÁTRA mountains after isotope Investigations. Proc. $2^{\text {nd }}$ Intl. Symp. on the mineral deposits of the Alps. Ljubljana, Yugoslavia, 383-390.

Malinin, S. D., KRopotova, O. I. and GRINENKo, V. A. (1967) Experimental determination of the isotopic exchange constant of carbon in the system $\mathrm{CO}_{2}$ gas $-\mathrm{HCO}_{3}^{-}$liquid at hydrothermal conditions. Geokhimiya 16, 927-935.

O'Neil, J. R., Clayton, R. N. and Mayeda, T. K. (1969) Oxygen isotope fractionation in divalent metal carbonates. J. Chem. Phys. 51, 5547-5558.

Robinson, B. W. (1974) The origin of the mineralization at the Tui Mine, TE AROHA, New Zealand, in the light of stable isotope studies. Econ. Geol. 69, 910-925.

SCHOELL, M. and STAHL, W. (1969) C- und O-Isotopenanalysen an hydrothermalen Kalkspaten aus St. Andreasberg, Harz. Conference on Stable Isotopes, Leipzig. (manuscript) 